\title{
CARRAPATICIDAS E INSETICIDAS NO CONTROLE QUÍMICO DE TRIATOMÍNEOS
}

\author{
Willian Marinho Dourado Coelho ${ }^{1}$, Edilson Silva de Oliveira ${ }^{2}$, Wilma Aparecida Starke Buzetti ${ }^{3}$ \\ ${ }^{1}$ Universidade Estadual Paulista - UNESP, Faculdade de Engenharia de Ilha Solteira, Ilha Solteira, SP. ${ }^{2}$ Faculdade de \\ Ciências Agrárias de Andradina - FCAA, Andradina, SP. ${ }^{3}$ Universidade Estadual Paulista Júlio de Mesquita Filho - \\ UNESP, Presidente Prudente, SP.
}

\section{RESUMO}

Diversos trabalhos foram realizados ao longo da história do Brasil com o intuito de se controlar e erradicar os bichos barbeiros do ambiente habitado por seres humanos, incluindo a realização de controle químico com hexaclorociclohexanos. O objetivo desta pesquisa foi avaliar a eficácia da acaricidas e inseticidas no controle de triatomíneos em municípios da região noroeste do Estado de São Paulo, Brasil. Foram capturados 94 triatomíneos com 81,91\% (77/94) da espécie T. sordida e 18,08\% (17/94) P. megistus. Os produtos a base de piretróides e imiprotrina associada a permetrina promoveram a morte $100 \%$ dos insetos em até 60 segundos. Observou-se que os produtos com maior taxa de letalidade também foram os que tiveram maior ação repelente. Os produtos a base de piretróide e citronela, imiprotrina associada a permetrina e a cipermetrina associada ao clorpirifós e citronelal repeliram os insetos por até 16 dias nos locais de aplicação. $O$ amitraz demonstrou eficácia reduzida no controle destas duas espécies de parasitos. Pode-se concluir com estes resultados que diferentes produtos químicos foram eficazes no controle de triatomíneos em áreas rurais da região noroeste do estado de São Paulo, sendo estes produtos, em sua maioria, apresentados comercialmente como carrapaticidas e inseticidas.

Palavras-chave: amitraz; carrapaticidas; inseticidas; quimioprofilaxia; Triatoma spp.

\section{ACARICIDES AND INSECTICIDES IN CHEMICAL CONTROL OF TRIATOMINE BUGS}

\begin{abstract}
Several studies have been conducted throughout the history of Brazil in order to control and eradicate barbers critters environment inhabited by human beings, including the completion of chemical control with hexaclorociclohexanos. The objective of this research was to evaluate the efficacy of miticides and insecticides in triatomine control in municipalities in the northwestern region of São Paulo, Brazil. 94 were captured triatomine with $81.91 \%$ (77/94) of the species T. sordida and $18.08 \%$ (17/94) P. megistus. The products based on pyrethroids and imiprothrin associated with permethrin promoted death $100 \%$ of the insects within 60 seconds. It was noted that products with higher mortality rate were also those who were more repellent action. The products based on pyrethroid and citronella, imiprothrin associated with permethrin and cypermethrin and chlorpyrifos associated with citronellal repelled the insects for up to 16 days application site. Amitraz showed reduced efficacy in controlling these two species of parasites. It can be concluded with these results that different chemicals were effective in triatomine control in rural areas of the northwest region of São Paulo, with these products, mostly commercially presented as acaricide and insecticides.
\end{abstract}

Keywords: amitraz; acaricides; insecticides; chemoprophylaxis; Triatoma spp.

\section{INTRODUÇÃO}

Existem aproximadamente 17 espécies de insetos incriminados como vetores do Trypanosoma cruzi. Mais importante, a sua totalidade possui hábitos preferencialmente domiciliares como é o caso do bicho barbeiro.
Estes insetos coabitam com seres humanos e animais de criação resultando na transmissão da tipanosomíase (SILVEIRA, 2000) Grande número de moléculas químicas têm sido empregadas para promover o controle desta praga sendo, os organoclorados, organofosforados, carbamatos e 
piretróides os inseticidas mais conhecidos e utilizado (ARGOLO et al., 2008). Entretanto, a persistência de focos destes parasitos em áreas submetidas a sucessivos ciclos de tratamento domiciliar ainda ocorrem nas mais diversas áreas do país (DIAS; ZERBA, 2001).

O objetivo desta pesquisa foi avaliar a eficácia de diferentes produtos químicos no controle de triatomíneos em municípios da região noroeste do Estado de São Paulo.

\section{METODOLOGIA}

A procura pelos parasitos iniciou-se nas propriedades rurais do município de Andradina, Itapura e Entre Rios-SP. Os parasitas foram localizados no interior de abrigos junto a chiqueiros, galinheiros e em áreas com entulho e madeira amontoados. Foram capturados 94 triatomíneos sendo que 81,91\% (77/94) eram da espécie $T$. sordida e 18,08\% (17/94) de $P$. megistus. Os insetos coletados foram colocados em recipientes plásticos perfurados em sua base e laterais para que, durante a pulverização, o excesso dos produtos pudesse escoar. Outra parte dos parasitas recebeu aplicação direta ainda no interior dos abrigos. Os produtos testados foram Cipermetrina $150 \mathrm{~g} / \mathrm{L}$ (Barrage ${ }^{\circledR}$ ), Piretróides (Baygon ${ }^{\circledR}$ ) Deltametrina 25,0 g/L (Butox $^{\circledR}$ ), Cipermetrina $10 \mathrm{~g} / \mathrm{L} \quad\left(\right.$ Cypermeit $\left.^{\circledR}\right)$, Cipermetrina $15,0 \mathrm{~g} / \mathrm{L}$ associada ao Clorpirifós 25,0g/L e Citronela 1,0 g/L (Colosso ${ }^{\circledR}$ ), Imiprotrina 0,015g/L e Permetrina 0,069g/L (Detefon ${ }^{\circledR}$ ) Diazinon 50,0g/L (Diazinon ${ }^{\circledR}$ ), Clorpirifós $50 \mathrm{~g} / \mathrm{L} \mathrm{e}$ Cipermetrina high-cis 6g/L (Flytion ${ }^{\circledR}$ ) e Amitraz 12,5g/L (Triatox ${ }^{\circledR}$ ), e preparados conforme recomendações do fabricante, sendo aplicados com a utilização de pulverizador costal manual de
10L (Guarany ${ }^{\circledR}$ ). A observação da morte dos insetos foi feita por inspeção visual, durante um período de 24 horas. A letalidade do produto foi considerada após a constatação da morte dos insetos e classificada como de eficácia nula (---) na ausência da morte dos parasitas, ruim (+) com morte em até 12 horas, regular $(++)$ com morte em até seis horas; bom (+++) com morte em até uma hora e excelente $(++++)$ com morte instantânea ou que não superasse 10 minutos. Como controle, foi pulverizado sobre os parasitos, minutos antes da aplicação dos inseticidas água mineral potável destinada ao consumo humano. Também foi realizada pulverização diretamente sobre os insetos ainda no interior dos abrigos observando-se o efeito repelente durante sete dias. A repelência foi avaliada com inspeção visual periódica dos abrigos durante sete dias ininterruptos, sendo classificado como elevada (ausência de triatomíneos por sete dias ou mais), moderada (ausência de triatomíneos por cinco dias), baixa (ausência de triatomíneos por três dias), nula (quando foram observados triatomíneos em qualquer um dos dois primeiros dias póspulverização).

\section{RESULTADOS}

Observou-se que os produtos com maior taxa de letalidade também foram os que tiveram maior ação repelente (Tabela 1). Os produtos a base de piretróide e citronela, cipermetrina associada ao clorpirifós, citronelal e também, a imiprotrina associada a permetrina repeliram os insetos por até 16 dias nos locais de aplicação. 0 amitraz demonstrou eficácia reduzida no controle destas duas espécies de parasitos.

Tabela 1. Eficácia da cipermetrina isolada, cipermetrina associada ao clorpirifós e citronelal, piretróides, deltametrina, imiprotrina associada permetrina e amitraz no controle de Triatoma sordida e Panstrongylus megistus em municípios da região noroeste do Estado de São Paulo.

\begin{tabular}{|c|c|}
\hline Composição/princípio ativo & Eficácia e repelência \\
\hline Cipermetrina $150 \mathrm{~g} / \mathrm{L}\left(\right.$ Barrage $^{\circledR}$ ) & $+++^{\mathrm{b}}$ \\
\hline Piretróides + citronela $\left(\right.$ Baygon $^{\circledR}$ ) & $++++^{a}$ \\
\hline Deltametrina $25,0 \mathrm{~g} / \mathrm{L}\left(\right.$ Butox $\left.^{\circledR}\right)$ & $++^{\mathrm{b}}$ \\
\hline Cipermetrina $10 \mathrm{~g} / \mathrm{L}\left(\right.$ Cypermeit $\left.^{\circledR}\right)$ & $++{ }^{b}$ \\
\hline Cipermetrina $15,0 \mathrm{~g} / \mathrm{L}+$ Clorpirifós $25,0 \mathrm{~g} / \mathrm{L}+$ Citronelal 1,0 g/L (Colosso ${ }^{\circledR}$ ) & $++++^{a}$ \\
\hline Imiprotrina, 0,015g/L + Permetrina 0,069g/L (Detefon ${ }^{\circledR}$ ) & $++++^{a}$ \\
\hline Diazinon 50,0g/L (Diazinon ${ }^{\circledR}$ ) & $++{ }^{b}$ \\
\hline Clorpirifós 50g/L + Cipermetrina high-cis 6g/L (Flytion ${ }^{\circledR}$ ) & $+++^{\mathrm{a}}$ \\
\hline Amitraz 12,5g/L (Triatox $\left.{ }^{\circledR}\right)$ & $+^{c}$ \\
\hline
\end{tabular}

Legenda: Letalidade: --- eficácia nula; + ruim; ++ regular; +++ bom; ++++ excelente

Repelência: a (elevada); b (moderada); c (baixa); d (nula) 


\section{DISCUSSÃO}

Em nosso estudo foi observado que alguns produtos apresentados comercialmente para promover a morte de carrapatos, pulgas, baratas, moscas e mosquitos podem atuar também com eficácia no controle e na repelência de triatomíneos. O produto BHC (hexabenzeno de cloro) foi utilizado por décadas no Brasil para controlar este artrópode. Em outros países, o Malathion e o Dieldrin também são explorados para esta finalidade. Entretanto, sua elevada toxicidade fez com que caíssem em desuso, sendo substituídos pelos compostos à base de piretróides. Segundo (FALAVIGNA-GUILHERME et al., 2002), a aplicação de cipermetrina $125 \mathrm{mg}$ i.a. $/ \mathrm{m}^{2}$ resultou na redução da infestação por triatomíneos em 80,6\% dos domicílios avaliados no estado do Paraná. Foi constatado em nosso estudo que a utilização da cipermetrina em concentrações maiores que a acima mencionada ou associada a outros princípios ativos também foram eficazes no controle da infestação pelos triatomíneos. Outros produtos como hexaclorobenzeno a $30 \%$ de isômero gama também são utilizados no controle da doença de Chagas, aplicados em ciclos semestrais. A periodicidade da aplicação destes inseticidas é superior ao obtido pelos produtos testados em nosso trabalho, cujo período máximo de repelência foi de 18 dias. Embora a aplicação de inseticidas se constitua numa importante

\section{REFERÊNCIAS}

ARGOLO, A.M.; FELIX, M.; PACHECO, R.; COSTA, J. Doença de Chagas e seus principais vetores no Brasil. Rio de Janeiro: Fundação Oswaldo Cruz, 2008. p.56.

DIAS, J.C.P.; ZERBA, E.N. Emprego do pote de fumígeno para proteção de insetário e sua ação residual contra triatomíneos, em condições de laboratório. Rev Soc Bras Med Trop., v.34, p.507-510, 2001.

FALAVIGNA-GUILHERME, A.L.; COSTA, A.L.; BATISTA, O.; PAVANELLI, G.C.; ARAÚJO, S.M. Atividade educativa para controle de triatomíneos em área de vigilância ferramenta no controle dos triatomíneos, a promoção da progressão socioeducativa da população humana por meio da melhoria da qualidade de vida, das habitações e hábitos de higiene adequados são os quesitos mais importantes na prevenção das infestações vetoriais, que atinge na maior parte das vezes as populações menos favorecidas pelos programas sociais do governo (ARGOLO et al., 2008). Por se tratarem de produtos de custo reduzido e que rendem grandes quantidades de soluções acaricidas e inseticidas, as informações contidas neste trabalho podem favorecer a adoção de medidas quimioprofiláticas por iniciativa da própria população, especialmente as mais carentes, contribuindo assim para redução da população dos vetores e das doenças por eles transmitidas.

\section{CONCLUSÃO}

Pode-se concluir com estes resultados que diferentes produtos químicos foram eficazes no controle de triatomíneos em áreas rurais da região noroeste do estado de São Paulo, sendo estes produtos, em sua maioria, apresentados comercialmente como carrapaticidas e inseticidas. Como se trata de produtos de baixo custo, estes princípios ativos podem constituir-se numa forma alternativa de controle de triatomíneos, ainda que a rotulagem do produto não 0 indique para tal finalidade.

epidemiológica do estado do Paraná, Brasil. Cadernos de Saúde Pública, v.18, n.6, p.15431550, 2002.

SILVEIRA, A.C. Situação do controle da transmissão vetorial da doença de Chagas nas Américas. Cad. Saúde Pública, Rio de Janeiro, v.16, (Sup. 2), p.35-42, 2000.

Recebido para publicação em 16/12/2016

Revisado em 18/02/2017

Aceito em 27/03/2017 